\title{
O ESCORPIONISMO NA ÁREA URBANA DE PALMAS-TOCANTINS
}

\section{SCORPIONISM IN THE URBAN AREA OF PALMAS-TOCANTINS}

\author{
Rodrigo Mendonça de Oliveira \\ Universidade Federal do Tocantins/UFT \\ drigopalmeirense@hotmail.com \\ Sandro Sidnei Vargas de Cristo \\ Universidade Federal do Tocantins/UFT \\ sidneicristo@uft.edu.br \\ Heguel Belmiro Souto de Albuquerque \\ Centro de Zoonoses de Palmas/TO \\ heguelbsa@yahoo.com.br \\ Késia Abreu dos Santos Porto \\ Universidade Federal do Tocantins/UFT \\ kesia abreu@hotmail.com \\ Jorge Luiz de Souza \\ Centro de Zoonoses de Palmas/TO \\ jorgeccz@hotmail.com \\ Carla Simone Seibert \\ Universidade Federal do Tocantins/UFT \\ seibertcs@uft.edu.br
}

\begin{abstract}
RESUMO
Este estudo objetivou analisar o perfil dos acidentes por escorpiões, em Palmas Tocantins. O tema foi escolhido devido ao processo de urbanização da cidade ter ocorrido desordenadamente, com a população ocupando locais com fauna bastante diversificada, entre elas a de escorpiões. Para avaliar o perfil epidemiológico dos acidentes e mapear as notificações realizadas no município, foram consultados os dados registrados entre o período de 2007 a 2013, junto ao Sistema de Informação de Agravos de Notificação. Com o intuito de identificar as espécies ocorrentes no município foi realizada busca ativa dos escorpiões nas residências, nas áreas de atividade coletiva da população ou áreas nativas da região. O perfil epidemiológico demonstrou frequência equivalente dos acidentes entre os indivíduos de ambos os sexos, com maior incidência de pessoas com idade entre 20 a 49 anos. Para o período de análise foram notificados 653 casos, sendo 521 no distrito sede do município. A espécie Tityus confluens foi a mais coletada, sendo possivelmente a responsável pela maioria dos acidentes. Sugere-se mobilização dos serviços de saúde para as áreas prioritárias do município e implementação de estratégias de vigilância e controle do escorpionismo.
\end{abstract}

Palavras-chave: Acidentes. Escorpiões. Epidemiologia.

\begin{abstract}
This study aimed to analyze the profile of accidents by scorpions in Palmas - Tocantins. The theme was chosen, due to the fact that the urbanization process of the city occurred in a disorderly manner, with the population occupying places with very diversified fauna, among them scorpions. To assess the epidemiological profile of accidents and map the notifications made in the district where the municipality is located, the data recorded between the period 2007-2013, with the Information System for Notifiable Diseases, were consulted. In order to identify the species occurring in the municipality, an active search for scorpions was carried out in homes, in areas of collective activity of the population or native areas of the region.
\end{abstract}

Recebido em: 31/01/2020

Aceito para publicação em: 05/08/2020. 
The epidemiological profile showed an equivalent frequency of accidents among individuals of both sexes, with a higher incidence of people aged between 20 and 49 years. For the analysis period, 653 cases were notified, 521 in the district where the municipality is located. The Tityus confluens species was the most collected, possibly being responsible for most accidents. It is suggested to mobilize health services to the priority areas of the municipality and implement strategies for surveillance and control of scorpionism.

Key word: Accidents. Scorpions. Epidemiology.

\section{INTRODUÇÃO}

A notória capacidade evolutiva e adaptativa dos escorpiões permitiu que esses animais resistissem a todos os grandes cataclismos. Os escorpiões se adaptaram aos mais variados tipos de habitat, dos desertos às florestas tropicais e do nível do mar a altitudes de até 5.500 metros, entretanto, a maioria das espécies tem preferência por climas tropicais e subtropicais (POLIS, 1990; GOPALAKRISHNAKONE et al., 2015).

Todos os escorpiões atuais são terrestres e podem ser encontrados nos mais variados ambientes, em esconderijos junto às habitações humanas, construções, e sob os dormentes das linhas dos trens (LIRA et al., 2005). Procuram locais escuros para se esconder e seu hábito noturno é registrado para a maioria das espécies, sendo mais ativos durante os meses mais quentes do ano (em particular no período das chuvas). No entanto, devido às alterações climáticas, em algumas regiões, estes animais se apresentam ativos durante o ano todo. São carnívoros, alimentam-se principalmente de insetos e aranhas, tornando-os um grupo de eficientes predadores de um grande número de pequenos animais, desempenhando um papel importante no equilíbrio ecológico como predadores de outros seres vivos, porém podem ocasionar acidentes quando em contato com humanos (POLIS, 1990). Os acidentes envolvendo escorpiões estão relacionados aos seus hábitos alimentares, forma de reprodução, proliferação das espécies e comportamento aliado às circunstâncias geradas pelo homem (CARDOSO, 2003; PRENDINI, 2005; GOPALAKRISHNAKONE et al., 2015).

Os escorpiões são animais peçonhentos, utilizam seu veneno para capturar e imobilizar suas presas, mas apenas 25 espécies em todo o mundo são potencialmente nocivas aos seres humanos (GOPALAKRISHNAKONE et al., 2015). No Brasil, a fauna de escorpiões é composta por cinco família, e a família Buthidae representa $60 \%$ do total de espécies, incluindo nesta o gênero Tityus, que é considerado de interesse em saúde pública. Contudo, nesse gênero quatro espécies se destacam por causar acidentes graves que podem levar à morte: Tityus serrulatus; Tityus bahienses, Tityus stigmurus e Tityus obscurus (MINISTÉRIO DA SAÚDE, 2009). Para o estado do Tocantins, as espécies de escorpiões mais relatadas são Tityus confluens, Tityus mattogrossensis, Jaguajir agamemnon e Opisthacanthus cayaporum (CARDOSO, 2003; GOPALAKRISHNAKONE et al., 2015; ESPOSITO et al., 2017).

Dependendo da intensidade dos sintomas clínicos o envenenamento por escorpião pode ser classificado em leve, moderado e grave. O acidente é considerado leve quando há somente manifestações clínicas locais (eritema, edema e dor), mas o acidentado pode apresentar náuseas, agitação e taquicardia leve. Nesses casos não há necessidade de administrar o soro antiescorpiônico. Os acidentes considerados de moderada gravidade apresentam, além dos sintomas locais, manifestações sistêmicas de baixa intensidade, como diaforese, náuseas, alguns episódios de vômito, taquicardia, taquipneia e hipertensão arterial. Já no acidente considerado grave, as manifestações sistêmicas são evidentes e intensas, com vômito intenso, salivação excessiva, diaforese profusa, hipotermia, taquidispneia, broncorreia, taqui e bradiarritmia, hiper ou hipotensão arterial, agitação e prostração alternada, podendo também ocorrer espasmos musculares e convulsão (CUPO, 2015).

O manual do Ministério da Saúde (2001) indica uso do soro antiescorpiônico para tratar os acidentes moderados e graves. Estudos mostram que a administração do soro é importante para neutralizar o efeito das toxinas que estão circulando no corpo da pessoa acidentada, no entanto, o soro não interfere na atividade dos mediadores que já podem estar agindo nos órgãos alvo, como o coração, o 
que exige mais cuidado com o paciente nas primeiras 24 horas de administração do soro (CUPO, 2015).

Os acidentes causados por animais peçonhentos constituem um problema de saúde pública, em 2019 causaram 265.701 acidentes com 438 óbitos no Brasil, sendo 58\% referente aos acidentes por escorpiões (SINAN, 2020). Os registros de acidentes por animais peçonhentos tornaram-se mais frequentes, não apenas na documentação hospitalar, mas nas matérias de jornais e obras de teor acadêmico. Destes, o escorpionismo vem adquirindo magnitude crescente e superando os acidentes por serpentes (PARDAL et al., 2003, LEOBAS et al. 2016; PARISI, 2016; SINAN 2020).

No estado do Tocantins, os acidentes por escorpiões chegaram a 4.967 casos somente no ano de 2019, com 2 óbitos (SINAN, 2020). Os estudos epidemiológicos realizados no estado identificam o escorpionismo como o responsável pelo maior registro de agravos por animais peçonhentos, sendo o município de Palmas - a Capital, responsável por grande parte desses registros (LEOBAS et al., 2016; PARISI, 2016). Dessa forma, faz se necessário analisar as condições que estão propiciando a proliferação desses animais e consequentemente, a ocorrência dos acidentes na capital, relacionando-os com fatores de ordem ambiental, urbanística, social e econômica das áreas afetadas. Para tanto, faz-se necessário identificar e conhecer a distribuição dos escorpiões prevalentes nas diferentes regiões da capital, a fim de, planejar e dimensionar as estratégias mais adequadas, para uma ação que permita a prevenção de acidentes e o controle destes animais na área urbana.

\section{METODOLOGIA}

\section{Área de estudo}

O estudo epidemiológico dos acidentes com escorpiões em Palmas foi realizado com base nos dados do Sistema de Informação de Agravos de Notificação (SINAN), obtidos na Secretaria de Saúde, no setor de Epidemiologia do município de Palmas. Como as notificações para os acidentes por escorpiões em Palmas foram realizadas com mais precisão a partir do ano de 2007, devido à modernização do sistema na área da informática, a pesquisa abordou esse período de investigação até o ano de 2013.

Para a análise do perfil epidemiológico dos acidentes por escorpiões foram consideradas as informações de todas as notificações realizadas para o município, independentemente da localização do acidente. As informações analisadas foram referentes: 1) ao indivíduo acidentado (idade, sexo e local do acidente); 2) ao quadro desencadeado pelo acidente, como o local da picada, tempo de atendimento, classificação do acidente (leve, moderado e grave), se houve tratamento com soroterapia e a evolução dos casos. Os resultados foram tabulados, separados por ano de ocorrência e realizada a análise descritiva dos mesmos. Para aferir a progressão anual dos acidentes, foi realizada análise de regressão linear, utilizando o programa GraphPad Prism 5.03.

As notificações foram agrupadas por zonas de ocorrência, considerando-se a zona urbana e rural. As notificações para a zona urbana foram separadas em Distrito Sede (Região Central, e Bairros da Região Sul) e Demais Distritos (Distrito de Taquaruçu e Buritirana). Para a Região Central foram consideradas as notificações registradas para o Setor Norte-quadras ao norte da Avenida JK (Figura 1, área delimitada em laranja); e Setor Sul-quadras ao sul da Avenida JK (Figura 1, área delimitada em azul). Já as notificações para os Bairros da Região Sul de Palmas foram aquelas cujo acidente ocorreu nos bairros Taquaralto, Aureny I, Aureny II, Aureny III, Aureny IV, Santa Fé, Morada do Sol, Bela Vista, Santa Bárbara, Setor Sul, Vale do Sol, Maria Rosa, Sol Nascente, Lago Sul, Setor Universitário, Setor Aeroporto, Setor Industrial, Santo Amaro, Água Fria, Marly Camargo, Taquari, Santa Helena, União Sul e Irmã Dulce (Figura 1, área delimitada em amarelo e marrom).

Para avaliar a evolução dos acidentes por escorpiões ao longo dos anos em estudo, foram analisadas as notificações ocorridas somente para o Distrito Sede do município (Figura 1), com base nos anos de 2007, 2010 e 2013. Não foram consideradas nesta análise as notificações dos Distritos de Buritirana e Taquaruçu. 
Figura 01 - Esquema de distribuição das quadras (Região Central) e Bairros (Região Sul) do Distrito Sede do município de Palmas-TO, segundo o Plano Diretor

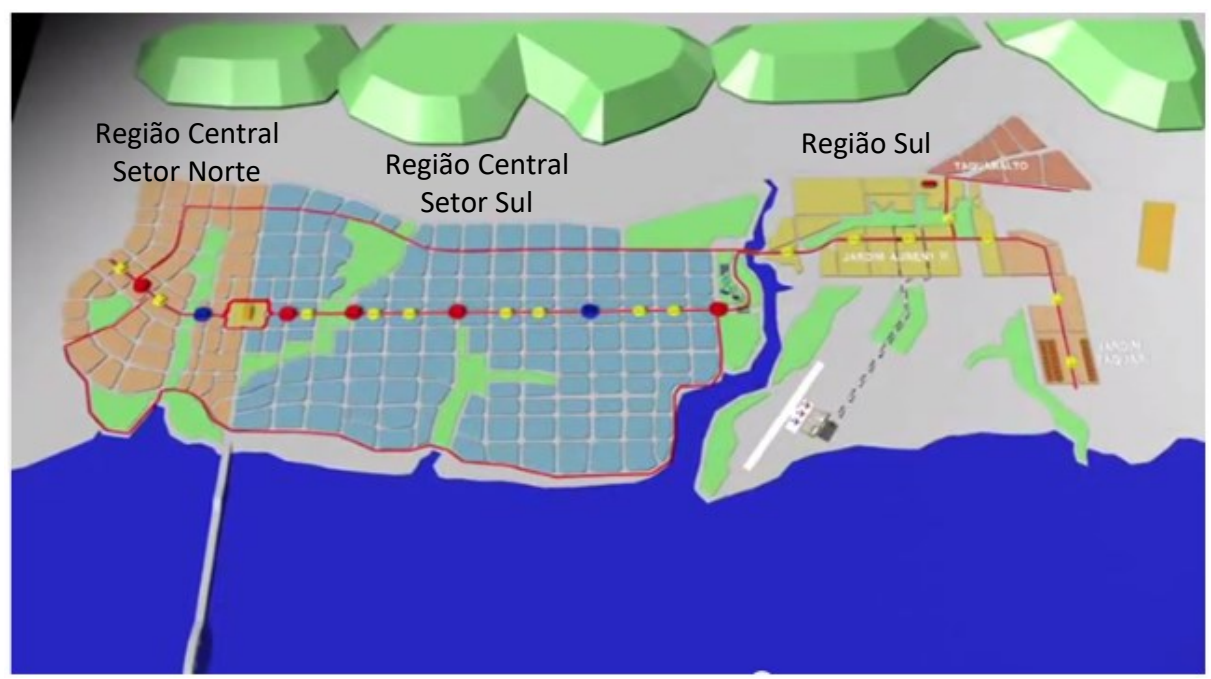

Fonte: Nortista (2014)

Legenda: Região Central (Setor Norte: laranja; Setor Sul: azul), Bairros da Região Sul (amarelo e marrom), Serra (elevação em verde claro)

Para avaliar a influência dos acidentes por escorpiões sobre o uso da terra, no distrito sede do município, foram elaborados mapas temáticos com emprego de imagens de satélite Landsat bandas 3,4 e 5 do INPE, do Instituto Nacional de Pesquisas Espaciais com base nos anos de 2007, 2010 e 2013. As classes temáticas utilizadas foram Campo; Cerrado Sentido Restrito; Cerradão; Mata de Galeria/Mata Ciliar; Área Urbanizada; Praia; Corpos D'Água Continental; e Agropecuária.

Para conhecer as espécies dos escorpiões de ocorrência no Distrito Sede do município, foram realizadas buscas ativas nas casas, áreas de atividade coletiva da população ou áreas nativas, por Agentes de Combate as Endemias (ACE). Além de exemplares entregues pela população acidentada nas Unidades de Pronto Atendimento dos Setores Norte e Sul (UPA), Hospital Infantil de Palmas (HIP) e Hospital Geral de Palmas (HGP), no período de agosto de 2013 a agosto de 2014. Os escorpiões foram identificados pela equipe da Unidade de Vigilância e Controle de Zoonoses (UVCZ) do município. As espécies coletadas foram armazenadas em frascos contendo álcool $70 \%$, registrando-se o local e a data da coleta. A identificação das espécies foi realizada no laboratório da Unidade de Vigilância e Controle de Zoonoses, com base no catalogo do Manual de Escorpião do Ministério da Saúde (2009) e em trabalhos científicos da área (LOURENÇO, 2002; LOURENÇO et al., 2004; ESPOSITO et al. 2017). Com os dados da coleta elaborou-se um mapa de distribuição destas espécies.

Os mapas foram elaborados com a utilização do software Esri/ArcGis 10.2. Os planos de informação $(P / s)$, foram editados a partir da Base Cartográfica Digital referente às quadras de Palmas disponibilizado em formato DWGnosite da Prefeitura Municipal Palmas, por meio do link SIGPALMAS. Nesse procedimento foi necessário converter os dados do formato (DWG) para o formato shapefile/ESRI, concluindo essa etapa foi adicionado a esse dado um Sistema de Projeção: Universal Transversa de Mercator UTM com Datum referencial Geodésico Brasileiro SIRGAS 2000 / Zona: 22 Sul, para ser editado no Sistema de Informações Geográficas - (SIG).

${ }_{1}$ Disponível em: <http://www.skyscrapercity.com/showthread.php?t=1707463\&page=2>

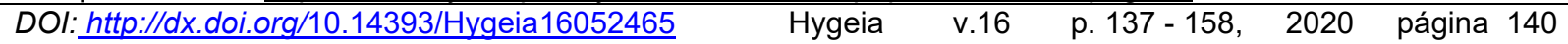




\section{RESULTADOS E DISCUSSÃO}

Para desenvolver essa pesquisa foram avaliados 653 acidentes por escorpiões, notificados no Sistema de Informação de Agravos de Notificação (SINAN), pelos hospitais e postos de saúde do município de Palmas. Estes apresentaram aumento dos acidentes registrados ao longo dos 7 anos em análise, com $22 \%$ dos dados notificados somente para o ano de 2013, 113 notificações a mais do que as registradas para o ano de 2007 (Tabela 1).

Os acidentes por escorpiões ocorreram com indivíduos de ambos os sexos e em proporções muito semelhantes, 332 acidentes (51\%) para o sexo masculino e 321 acidentes (49\%) para o sexo feminino. Dos 653 acidentes notificados nestes 7 anos de estudo, 105 acidentes (16\%) envolveram crianças até 9 anos de idade e 358 acidentes (55\%) foram notificados para pessoas com idade mais ativa, entre 20 a 49 anos. A maioria dos acidentes ocorreu fora do local de trabalho (550 acidentes, $84 \%$ ), podendo ser na residência do acidentado ou em área de lazer (Tabela 1). Muitos acidentes com escorpiões ocorrem dentro das residências, pelo fato de ser um local com histórico de presença abundante de baratas, que são comumente utilizadas como alimento por esses animais, facilitando sua proliferação.

Tabela 01 - Perfil dos acidentes por escorpiões no município de Palmas-TO, entre 2007 a 2013

\begin{tabular}{lcccccccc}
\hline \multicolumn{8}{c}{ Sexo } \\
\hline & $\mathbf{2 0 0 7}$ & $\mathbf{2 0 0 8}$ & $\mathbf{2 0 0 9}$ & $\mathbf{2 0 1 0}$ & $\mathbf{2 0 1 1}$ & $\mathbf{2 0 1 2}$ & $\mathbf{2 0 1 3}$ & Total \\
\hline Masculino & 23 & 33 & 65 & 45 & 43 & 58 & 65 & 332 \\
Feminino & 15 & 26 & 55 & 43 & 52 & 50 & 80 & 321 \\
\hline \multicolumn{8}{c}{ Faixa etária } \\
\hline$<1-9$ & 3 & 15 & 21 & 9 & 10 & 24 & 23 & 105 \\
$10-19$ & 8 & 15 & 20 & 13 & 17 & 20 & 26 & 109 \\
$20-34$ & 16 & 17 & 37 & 42 & 33 & 38 & 55 & 238 \\
$35-49$ & 5 & 7 & 34 & 14 & 21 & 15 & 24 & 120 \\
$50-64$ & 4 & 5 & 6 & 8 & 11 & 9 & 13 & 56 \\
$65-79$ & 2 & 0 & 2 & 2 & 2 & 2 & 3 & 13 \\
80 e & 0 & 0 & 0 & 0 & 1 & 0 & 1 & 2 \\
\hline \multicolumn{7}{c}{ Acidente ocorrido no trabalho? } \\
\hline Sim & 11 & 23 & 12 & 17 & 17 & 17 & 103 \\
Não & 27 & 53 & 97 & 76 & 78 & 91 & 128 & 550 \\
\hline Total & $\mathbf{3 8}$ & $\mathbf{5 9}$ & $\mathbf{1 2 0}$ & $\mathbf{8 8}$ & $\mathbf{9 5}$ & $\mathbf{1 0 8}$ & $\mathbf{1 4 5}$ & $\mathbf{6 5 3}$ \\
\hline \multicolumn{8}{c}{ Fonte: SINAN (2014). }
\end{tabular}

Os escorpiões habitam qualquer lugar, desde que tenham como se alimentar, desta forma, podem viver em áreas rurais ou urbanas, se alojar em residências ou ambiente de trabalho (LOURENÇO, 1980). Estes animais procuram alimento durante a noite, entram nos ambientes através da tubulação para fiação elétrica e encanamento de esgoto, além de frestas de paredes, portas e janelas (PRENDINI, 2005). Podem se esconder da claridade do dia em lugares escuros como dentro de calçados, armários, gavetas, panos e toalhas, em áreas de serviço e banheiros, o que favorece a exposição de crianças e donas de casa a estes acidentes, por permaneceram mais tempo dentro ou no entorno do domicílio. Contudo, os acidentes com escorpiões também ocorrem em pessoas que atuam na construção civil, trabalhadores de madeireiras, transportadoras e distribuidoras de hortifrutigranjeiros, pois estes podem manusear objetos e alimentos que alojam esses animais (LOURENÇO, 2002; TORRES et al., 2002).

O atributo mais notório de um escorpião é seu ferrão/veneno e todas as espécies são venenosas, para os insetos, que são seu alimento potencial. No entanto, entre todas as espécies de escorpiões conhecidas, apenas um pequeno número é perigoso para os seres humanos (GOPALAKRISHNAKONE et al., 2015). Embora não ataquem o homem intencionalmente, os acidentes com escorpiões ocorrem no momento em que o indivíduo encosta a mão, o pé ou outra parte do corpo no animal. Por serem muito pequenos, estes 
se escondem em qualquer lugar e ficam horas ou dias sem se locomoverem, basta então alguém distraído encostar no animal e o acidente acontece. $O$ veneno da maioria dos escorpiões produz uma reação semelhante à da ferroada da abelha, que é muito dolorosa, e em muitos casos não oferece perigo de morte aos humanos (POLIS, 1990).

O quadro clínico dos acidentes por escorpiões, registrado para o presente estudo, está apresentado na tabela 2. As mãos (176 casos, $27 \%$ ) e os dedos das mãos (124 casos, 19\%) foram as partes do corpo mais acometidas. Para 422 acidentes $(65 \%)$ o tempo de atendimento não foi registrado, para outros 149 acidentes $(23 \%)$, o paciente recebeu atendimento médico em até 1hora após o acidente. Dos 653 acidentes, apenas 6 acidentes $(0,91 \%)$ foram classificados como graves, os demais como moderados (262 acidentes, 40\%) e leves (385 acidentes, 59\%). Das pessoas acidentadas, 301 (46\%) foram tratadas com soroterapia e a maioria evoluiu para a cura, sem sequelas (649 acidentados, $99 \%$ ).

Tabela 02 - Perfil clínico dos acidentes ocasionados por escorpião no município de Palmas-TO, entre 2007 a 2013

\begin{tabular}{|c|c|c|c|c|c|c|c|c|}
\hline \multicolumn{9}{|c|}{ Local picada } \\
\hline & 2007 & 2008 & 2009 & 2010 & 2011 & 2012 & 2013 & Total \\
\hline Braço & 1 & 3 & 3 & 4 & 3 & 5 & 6 & 25 \\
\hline Ante-Braco & 1 & 1 & 0 & 2 & 3 & 3 & 3 & 13 \\
\hline Mão & 7 & 13 & 34 & 26 & 29 & 28 & 39 & 176 \\
\hline Dedo da mão & 14 & 14 & 23 & 15 & 9 & 19 & 30 & 124 \\
\hline Tronco & 1 & 4 & 7 & 4 & 4 & 7 & 5 & 32 \\
\hline Coxa & 1 & 1 & 5 & 3 & 6 & 7 & 6 & 29 \\
\hline Perna & 1 & 1 & 10 & 8 & 11 & 7 & 8 & 46 \\
\hline Pé & 9 & 16 & 33 & 19 & 24 & 21 & 37 & 159 \\
\hline Dedo do pé & 3 & 3 & 2 & 6 & 4 & 7 & 10 & 35 \\
\hline \multicolumn{9}{|c|}{ Tempo de atendimento } \\
\hline Ign/Branco & 18 & 37 & 72 & 63 & 57 & 77 & 98 & 422 \\
\hline $0-1$ horas & 15 & 16 & 27 & 13 & 26 & 20 & 32 & 149 \\
\hline 1-3 horas & 4 & 1 & 14 & 10 & 8 & 8 & 7 & 52 \\
\hline 3-6 horas & 0 & 1 & 3 & 2 & 3 & 1 & 3 & 13 \\
\hline 6-12 horas & 1 & 3 & 0 & 0 & 1 & 1 & 0 & 6 \\
\hline $12 e+$ horas & 0 & 1 & 4 & 0 & 0 & 1 & 5 & 11 \\
\hline \multicolumn{9}{|c|}{ Classificação dos acidentes } \\
\hline Leve & 22 & 41 & 81 & 34 & 57 & 64 & 86 & 385 \\
\hline Moderado & 15 & 16 & 37 & 54 & 38 & 43 & 59 & 262 \\
\hline Grave & 1 & 2 & 2 & 0 & 0 & 1 & 0 & 6 \\
\hline \multicolumn{9}{|c|}{ Soroterapia aplicada } \\
\hline Ign/Branco & 0 & 0 & 0 & 0 & 0 & 0 & 1 & 1 \\
\hline Sim & 20 & 21 & 60 & 57 & 42 & 44 & 57 & 301 \\
\hline Não & 18 & 38 & 60 & 31 & 53 & 64 & 87 & 351 \\
\hline \multicolumn{9}{|c|}{ Evolução dos casos } \\
\hline Cura & 38 & 59 & 120 & 88 & 95 & 108 & 141 & 649 \\
\hline Cura/seqüela & 0 & 0 & 0 & 0 & 0 & 0 & 4 & 4 \\
\hline Total & 38 & 59 & 120 & 88 & 95 & 108 & 145 & 653 \\
\hline
\end{tabular}

O número de acidentes cuja picada ocorreu na mão e dedo da mão (300 acidentes, 46\%), evidencia um acidente ocasional e a falta de atenção do acidentado em observar o que está manipulando. Cupo et al. (2003) registraram que cerca de $74 \%$ dos acidentes com escorpiões ocorreram nas mãos e pés, corroborando com a perspectiva da desatenção por parte da população. Neste caso, serve como recomendação a utilização de Equipamentos de Proteção Individual (EPI) nas mãos e pés (áreas mais afetadas), como luvas e calçados adequados para prevenir acidentes. 
Geralmente, o acidente por escorpião é seguido de dor (moderada ou intensa) com outras manifestações clínicas, dependendo da sua gravidade (CUPO, 2015). Os acidentes leves podem ser tratados com analgésico ou anestésicos, contudo, deve-se ficar atendo para o surgimento de outros sintomas por no mínimo 24 horas, principalmente em crianças menores de 7 anos, idosos ou portador de alguma comorbidade (PARDAL et al., 2003; CUPO, 2015).

Segundo o Ministério da Saúde (2001) a soroterapia para o tratamento destes pacientes é realizada para os acidentes com manifestações clínicas mais graves. Nesse estudo, 301 acidentados $(46 \%)$ foram tratados com soro antiescorpiônico, para $268(41 \%)$ que tiveram seu quadro clinico classificado como moderado e grave (Tabela 2). Portanto, 33 pacientes acidentados por escorpião, classificados como leves, também receberam tratamento com soro antiescorpiônico.

É importante destacar a aumento crescente no registro de acidentes por escorpiões no município de Palmas, ao longo dos 7 anos em estudo, o que foi confirmado estatisticamente pela análise de regressão linear $\left(p=0,0197 ; r^{2}=0,6954\right)$.

Para entender melhor as questões envolvidas com o aumento dos acidentes por escorpiões no Distrito Sede, as notificações foram organizadas por zona de ocorrência e região, e estão apresentados na tabela 3. Dos 653 acidentes notificados no período de 2007 a 2013, 556 acidentes $(85 \%)$ ocorreram na zona urbana e desses, 521 acidentes $(80 \%)$ foram notificados para o Distrito Sede do município de Palmas.

Com base nestes dados, foram elaborados mapas de evolução dos acidentes por escorpiões, para o Distrito Sede do município, para os anos de 2007, 2010 e 2013 (Figura 2). Os resultados deixaram evidente o aumento das notificações dos acidentes por escorpiões no Distrito Sede e dos locais onde estes ocorreram. Ao analisar os acidentes notificados para a Região Central no Setor Norte do município houve um aumento nos números de acidentes em 2010, principalmente nas ARNO 33, 43, 44, 73, 72 e 71, quando comparado com o registro para 2007. Em 2013 ocorreu o maior número de notificações para estes acidentes, distribuído de forma mais abrangente em todo o Setor (Tabela 3; Figuras 3, 4 e 5).

Na Região Central no Setor Sul de Palmas, para o ano de 2007, houve o registro de 9 acidentes, o que se elevou para 22 em 2010, e dobrou em 2013 (43 acidentes registrados). O aumento dos registros foi acompanhado da ampliação das quadras notificadas com acidentes por escorpiões (Tabela 3; Figuras 6, 7 e 8).

Já para os Bairros da Região Sul, em 2007, foram poucos os acidentes notificados, com registros em Taquaralto e Taquari. O número de bairros com notificações de acidentes aumentou no período em estudo, no entanto, o bairro Taquari desde 2011 apresentou maior número de acidentes (Jardim Taquari está localizado na Figura 10 - área preenchida em marrom; e na Figura 11 - área preenchida em vermelho).

Os Bairros da Região Sul, do Distrito Sede, registraram o maior número de acidentes (230 casos, $41 \%$ ), esta parte do município não foi contemplada pelo Plano Diretor. Portanto nesta área não houve uma organização planejada e também é onde se localiza o maior percentual de pessoas com baixa renda. Dessa forma, apesar de Palmas ser uma cidade planejada e jovem, possui diversas áreas periféricas com acessibilidade e infraestrutura limitada, onde o solo é menos valorizado e ocupado, basicamente, por populações de baixa renda, que vivem em evidentes condições de precariedade econômica, social e ambiental, tendo, por consequência, a sua qualidade de vida comprometida (PALMAS, 2002; KRAN \& FERREIRA, 2006; CARVALHÊDO, 2007), o que pode fragilizar a sua saúde e possibilitar maior ocorrência do escorpionismo.

É possível avaliar a expansão urbana do Distrito Sede de Palmas analisando o mapa de uso da terra (Figura 12), no qual foi visível a transformação de áreas de agricultura e/ou áreas verde em áreas urbanizadas, com destaque para as periferias do Distrito Sede. No ano de 2007 foi observada a presença de áreas de agropecuária na Região Central (Setor Norte e Setor Sul) de Palmas, e áreas significativas de cerrado sentido restrito, ao Sul do Distrito. As áreas de agropecuária foram sendo substituídas pelo cerrado sentido restrito ou por área urbana nos anos seguintes. 
Tabela 03 - Distribuição dos acidentes por escorpião, por Zona e Distrito do município de Palmas-TO, entre 2007 a 2013

\begin{tabular}{lcccccccc}
\hline & \multicolumn{7}{c}{ Distribuição dos acidentes por Zona } \\
\hline & $\mathbf{2 0 0 7}$ & $\mathbf{2 0 0 8}$ & $\mathbf{2 0 0 9}$ & $\mathbf{2 0 1 0}$ & $\mathbf{2 0 1 1}$ & $\mathbf{2 0 1 2}$ & $\mathbf{2 0 1 3}$ & Total \\
\hline Zona Urbana & 33 & 53 & 99 & 75 & 75 & 91 & 130 & 556 \\
Zona Rural & 5 & 6 & 21 & 10 & 19 & 15 & 21 & 97 \\
\hline Total & $\mathbf{3 8}$ & $\mathbf{5 9}$ & $\mathbf{1 2 0}$ & $\mathbf{8 5}$ & $\mathbf{9 4}$ & $\mathbf{1 0 6}$ & $\mathbf{1 5 1}$ & $\mathbf{6 5 3}$ \\
\hline \multicolumn{7}{c}{ Distribuição dos acidentes na Zona Urbana } \\
\hline Distrito Sede & \multicolumn{1}{c}{} & & & & & & \\
Região Central-Setor Norte & 12 & 12 & 20 & 14 & 15 & 17 & 20 & 110 \\
Região Central-Setor Sul & 9 & 27 & 32 & 22 & 25 & 23 & 43 & 181 \\
Bairros da Região Sul & 11 & 13 & $\mathbf{4 2}$ & 31 & 30 & 48 & 55 & 230 \\
Demais Distritos & 1 & 1 & 5 & 8 & 5 & 3 & 12 & 35 \\
\hline Total & $\mathbf{3 3}$ & $\mathbf{5 3}$ & $\mathbf{9 9}$ & $\mathbf{7 5}$ & $\mathbf{7 5}$ & $\mathbf{9 1}$ & $\mathbf{1 3 0}$ & $\mathbf{5 5 6}$ \\
\hline
\end{tabular}

Fonte: SINAN (2014).

Palmas é uma cidade em construção cuja vegetação está sendo modificada pela ocupação humana. As regiões mais periféricas são também aquelas que estão mais próximas das matas. Dessa forma, o aumento dos acidentes com escorpiões, ao longo destes anos, parece estar ligado ao crescimento urbano do município, em todas as áreas do Distrito Sede.

A remoção da vegetação causa quebra na cadeia alimentar dos escorpiões, acabando também com seus locais de abrigo. Com a escassez de alimento nas áreas nativas, esses animais passam a procurar alimento e abrigo em residências, terrenos baldios e áreas de construção. Locais onde há acúmulo de matéria orgânica, entulhos, lixos, depósitos e armazéns, oferecendo condições que propiciam a proliferação das baratas (Periplaneta americana, e outras espécies), devido a disponibilidade de alimento e umidade (LOURENÇO, 2002). Como os escorpiões têm as baratas como componente da sua cadeia alimentar, estes se deslocam para os lugares onde há abundância desse alimento, se aproximando mais da população.

Com a coleta dos escorpiões foi possível identificar quatro espécies: Tityus confluens, Tityus mattogrossensis, Tityus obscurus e Jaguajir agamemnon. Todas estas, relatadas para o estado do Tocantins e descritas para áreas de cerrado e de transição entre savanas e floresta amazônica (MAURY, 1974; LOURENÇO 2002; LOURENÇO et al., 2004; BRANDÃO \& MOTTA, 2010; GOPALAKRISHNAKONE et al., 2015). No período de 2013 a 2014 foram coletados 50 escorpiões, sendo predominantes as espécies de Tityus confluens (32 espécimes), seguido por Jaguajir agamemnon (13 espécimes), Tityus mattogrossensis (4 espécimes) e Tityus obscurus (1 espécime) (Figura 13). Tityus confluens foi o mais encontrado na Região Central do Distrito Sede, o que o coloca como a principal espécie causadora dos acidentes nessa área, e a espécie Jaguajir agamemnon foi localizada com predominância nos Bairros da Região Sul. Nestes anos de estudo, somente $15 \%$ dos registros de acidentes por escorpiões foram notificados para a zona rural (Tabela 1) e as quatro espécies foram encontradas nessa área do município, inclusive o espécime de Tityus obscurus. É importante ressaltar que a espécie Tytius obscurus é uma das quatro espécies consideradas de importância médica, por desencadear quadro clínico grave que pode levar o acidentado à óbito (Ministério da Saúde, 2009).

A presença dessa espécie no município destaca com mais veemência a necessidade de cuidados para reduzir o risco do acidente, sendo importante manter limpa a região peridomiciliar das residências, remover lixo, tijolos, pedras, madeiras, sempre usando equipamentos de proteção individual, especialmente luvas de couro. E ainda, vedar as soleiras das portas e colocar tela de proteção nas janelas, a fim de evitar o alojamento e proliferação destes animais nos ambientes ocupados pelo homem (MINISTÉRIO DA SAÚDE, 2009; LEOBAS et al., 2016). 
Figura 02 - Quadro resumo da evolução dos acidentes por escorpiões do Distrito Sede do município de Palmas-TO, nos anos de 2007,2010 e 2013

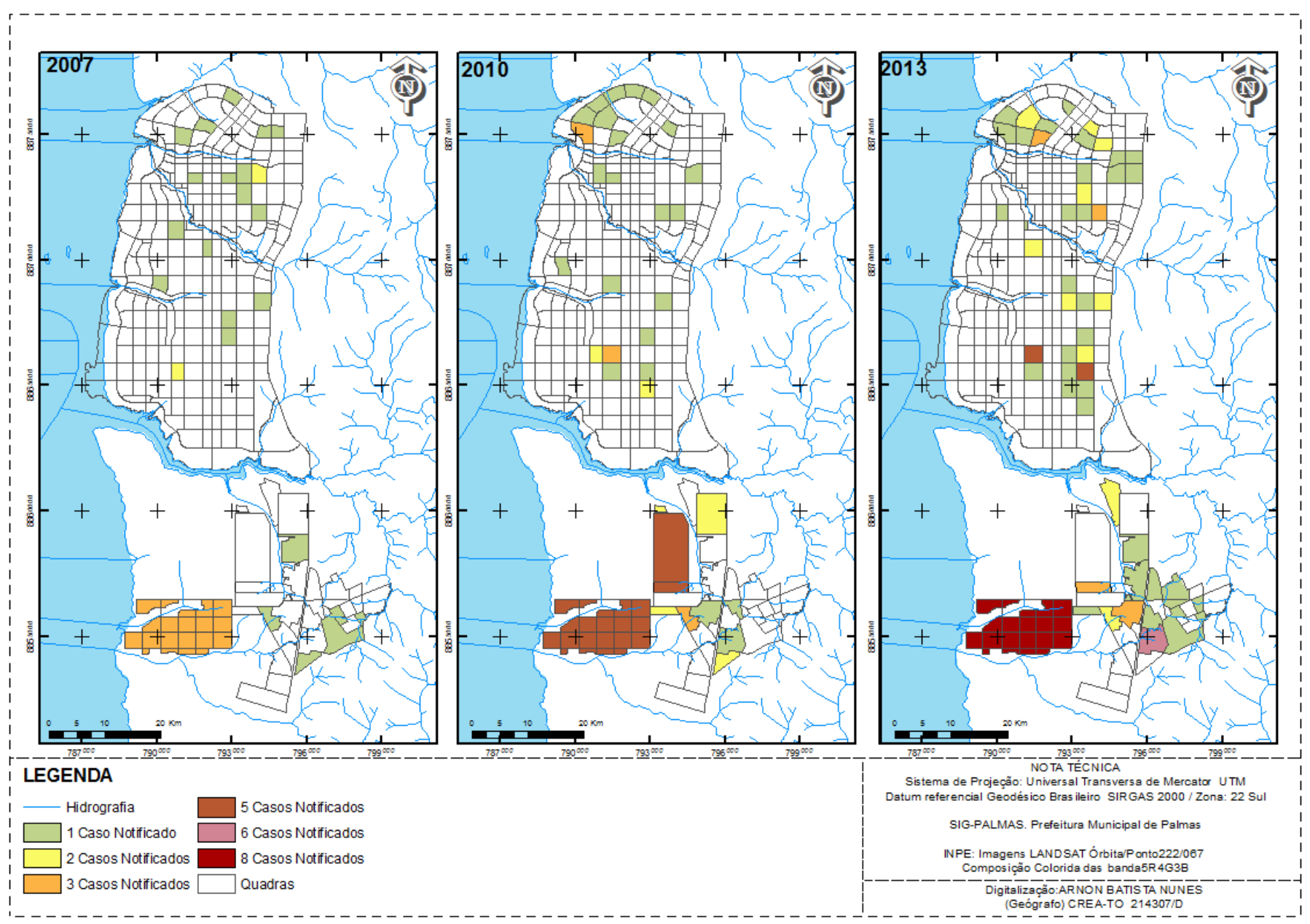

Fonte: Palmas (s/d); SINAN (2014) 
Figura 03 - Mapa de ocorrência dos acidentes por escorpiões na Região Central - Setor Norte do Distrito Sede do município de Palmas-TO, em 2007

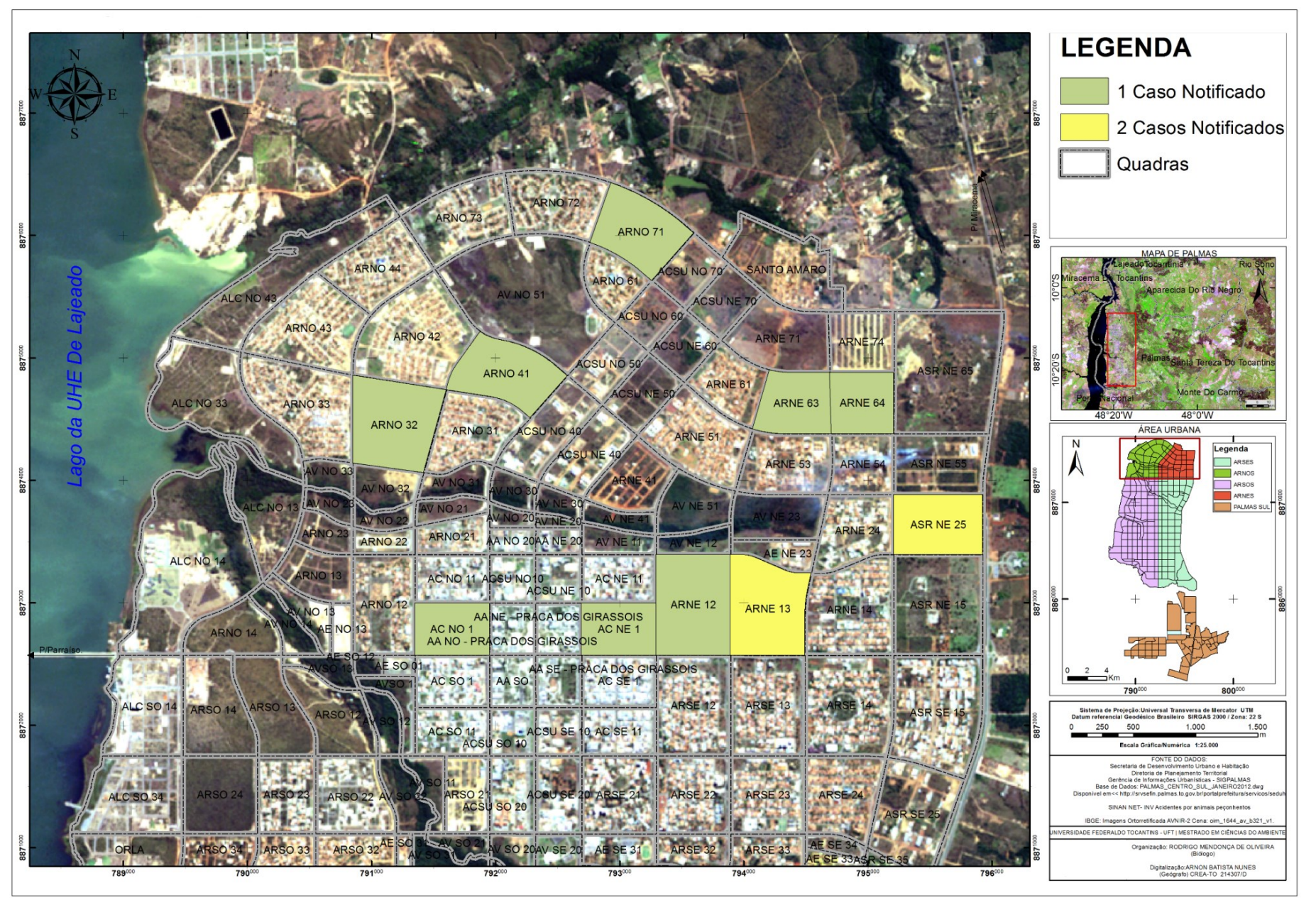


Figura 04 - Mapa de ocorrência dos acidentes por escorpiões na Região Central - Setor Norte do Distrito Sede do município de Palmas-TO, em 2010
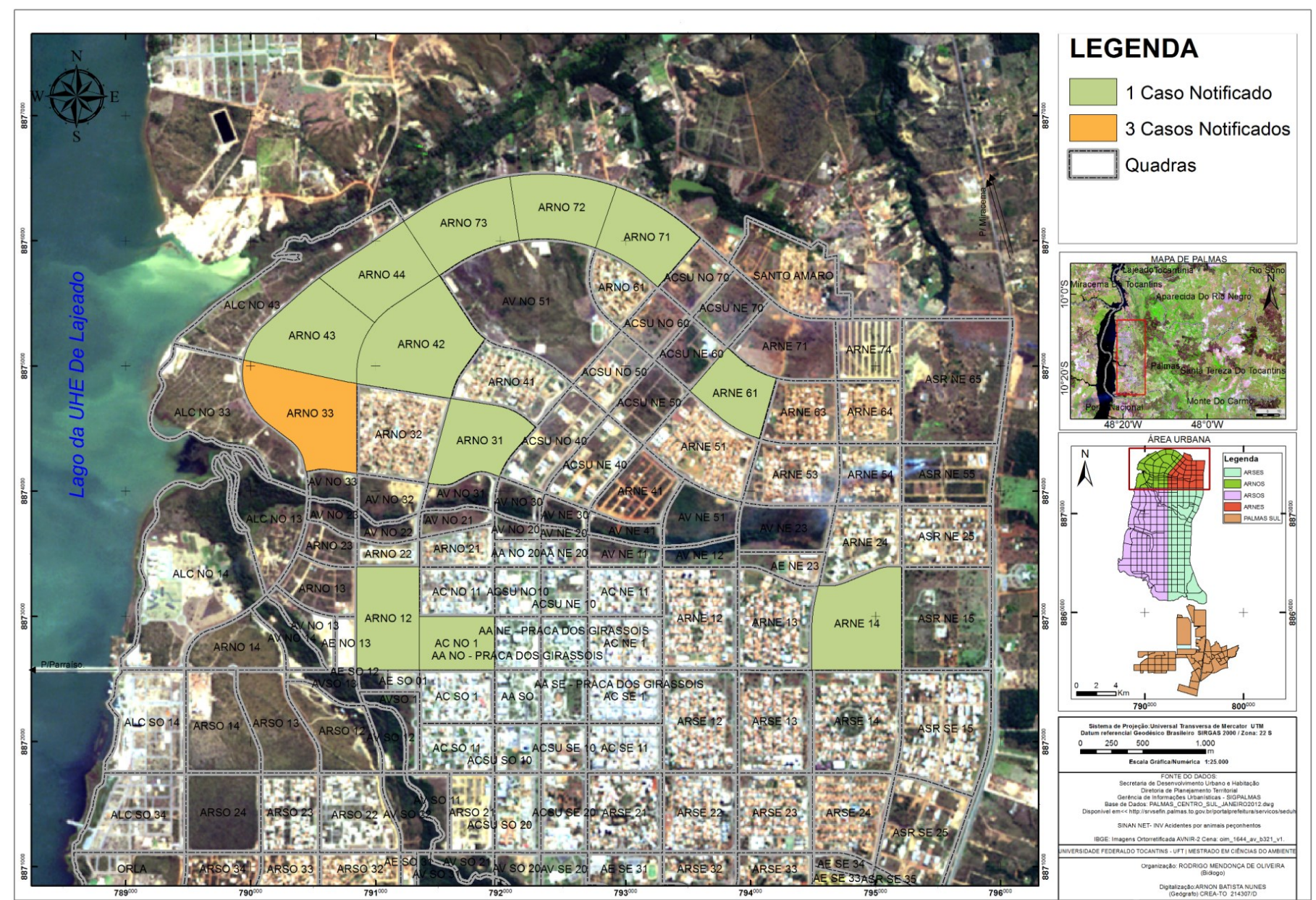
Figura 05 - Mapa de ocorrência dos acidentes por escorpiões na Região Central - Setor Norte do Distrito Sede do município de Palmas-TO, em 2013

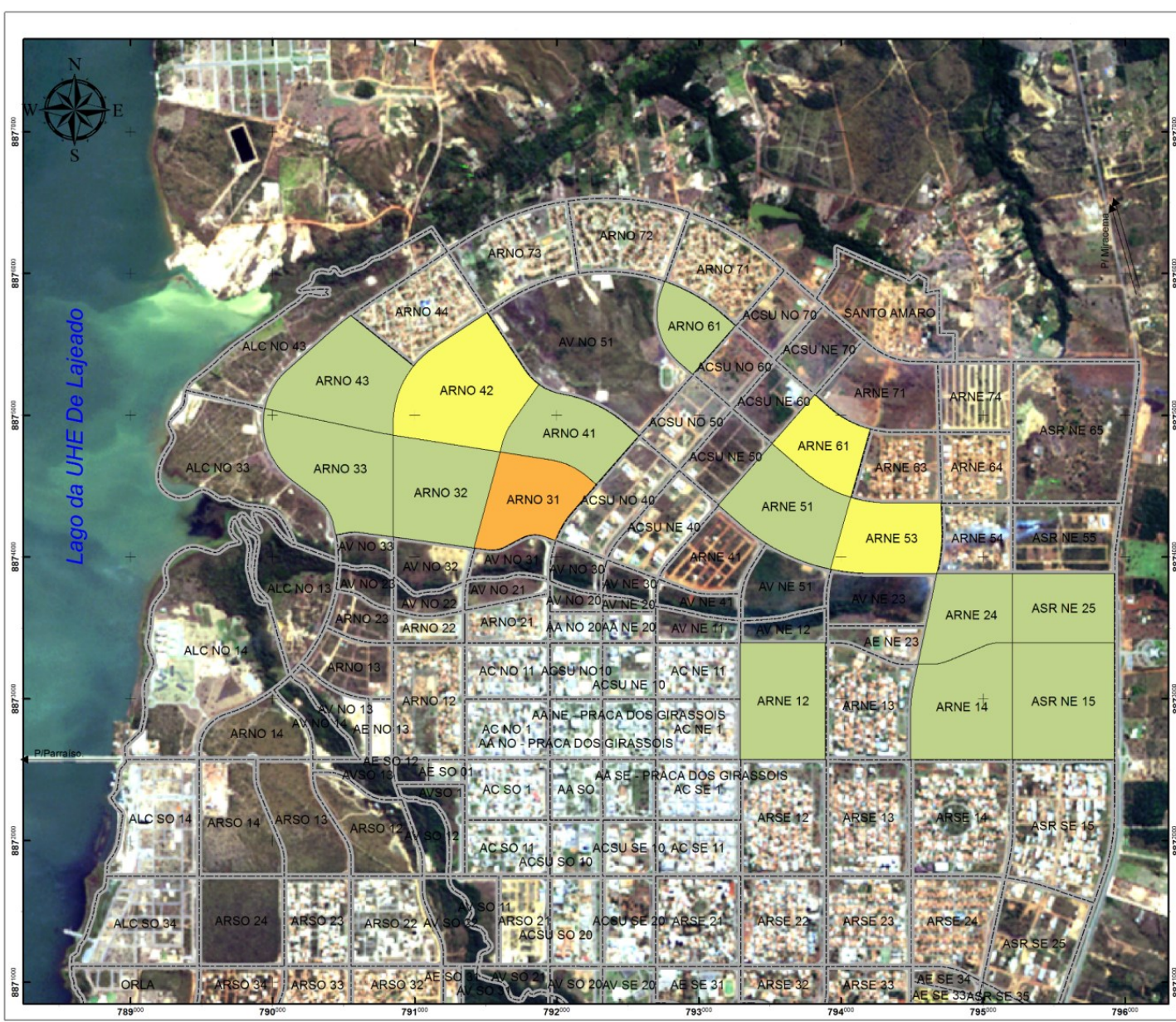

\section{LEGENDA}

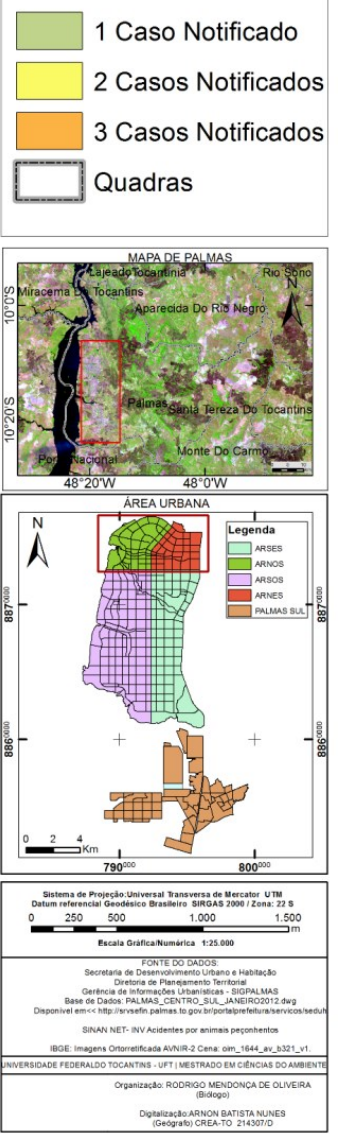


Figura 06 - Mapa de ocorrência dos acidentes por escorpiões na Região Central - Setor Sul do Distrito Sede do município de PalmasTO, em 2007

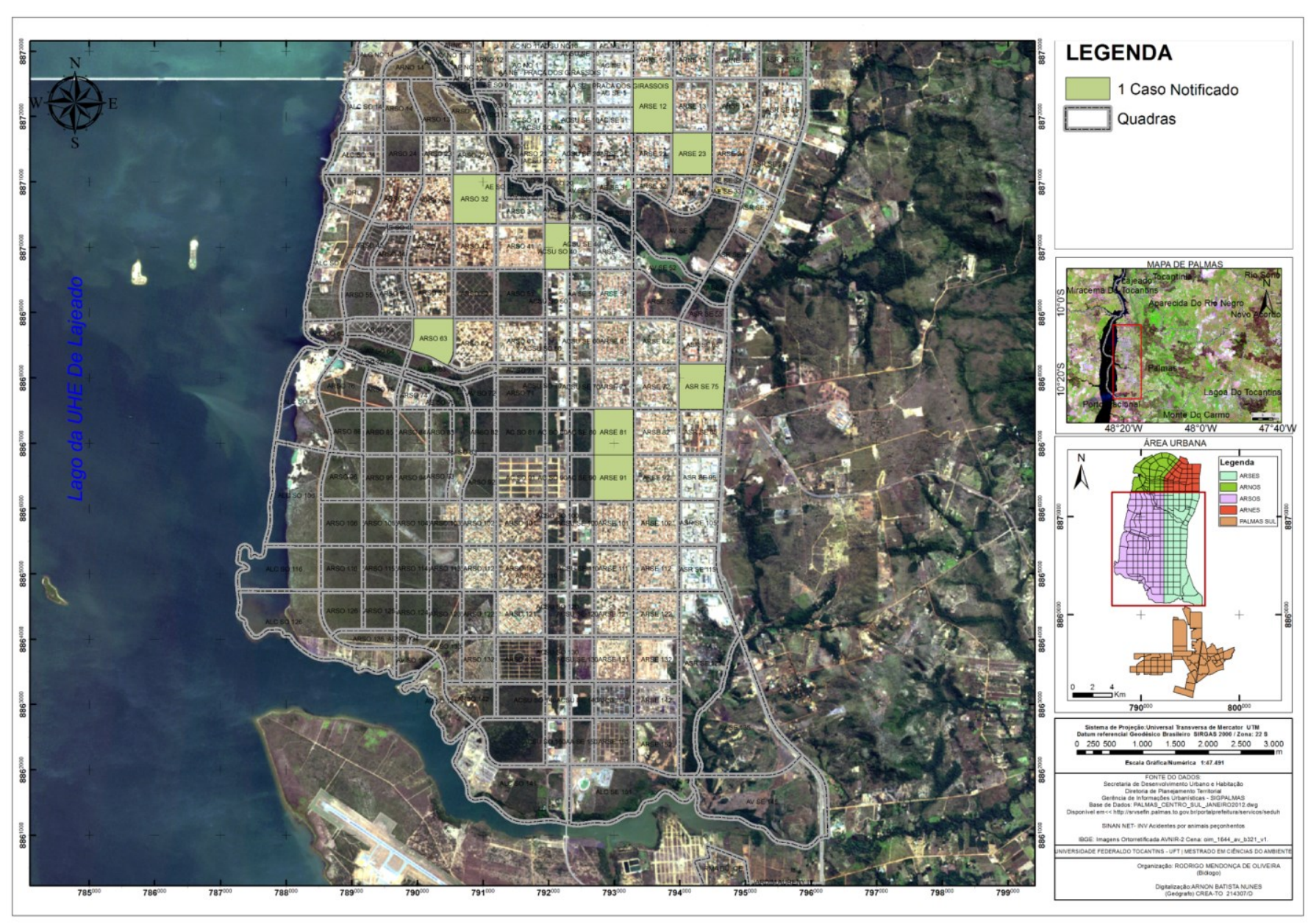


Figura 07 - Mapa de ocorrência dos acidentes por escorpiões na Região Central - Setor Sul do Distrito Sede do município de Palmas-TO, em 2010

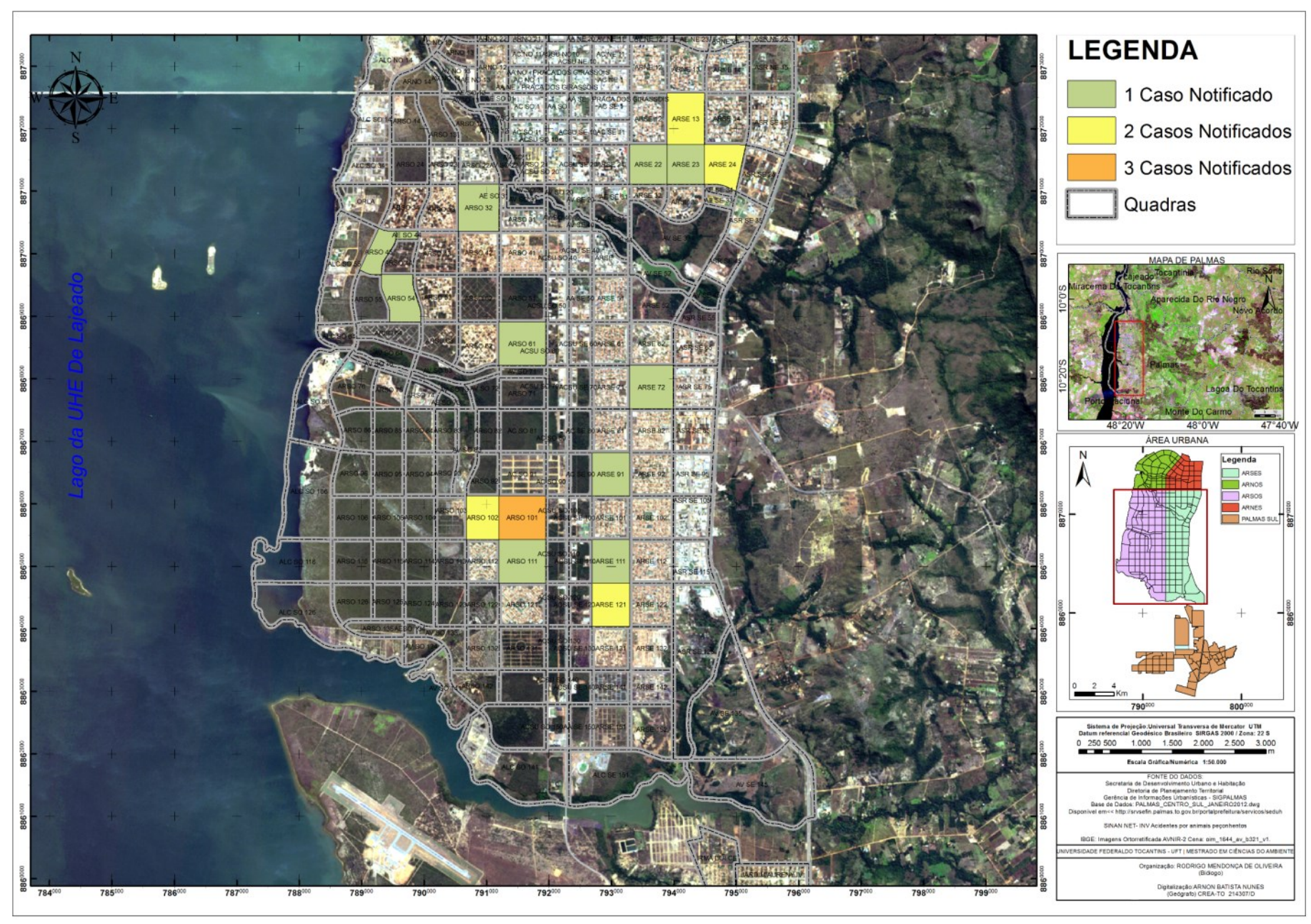


Figura 08 - Mapa de ocorrência dos acidentes por escorpiões na Região Central - Setor Sul do Distrito Sede do município de Palmas-TO, em 2013

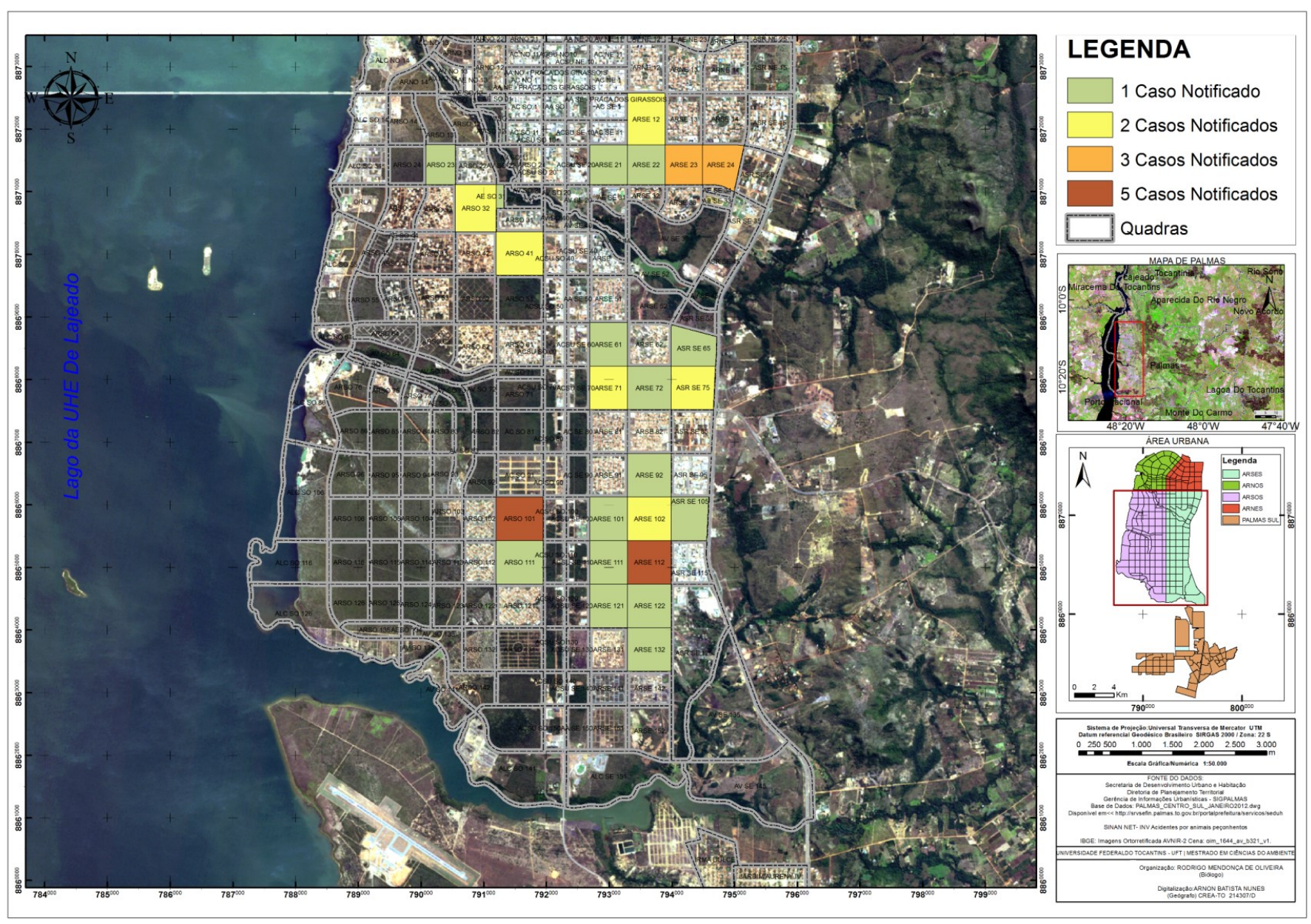


Figura 09 - Mapa de ocorrência dos acidentes por escorpiões nos Bairros da Região Sul do Distrito Sede do município de Palmas-TO, em 2007

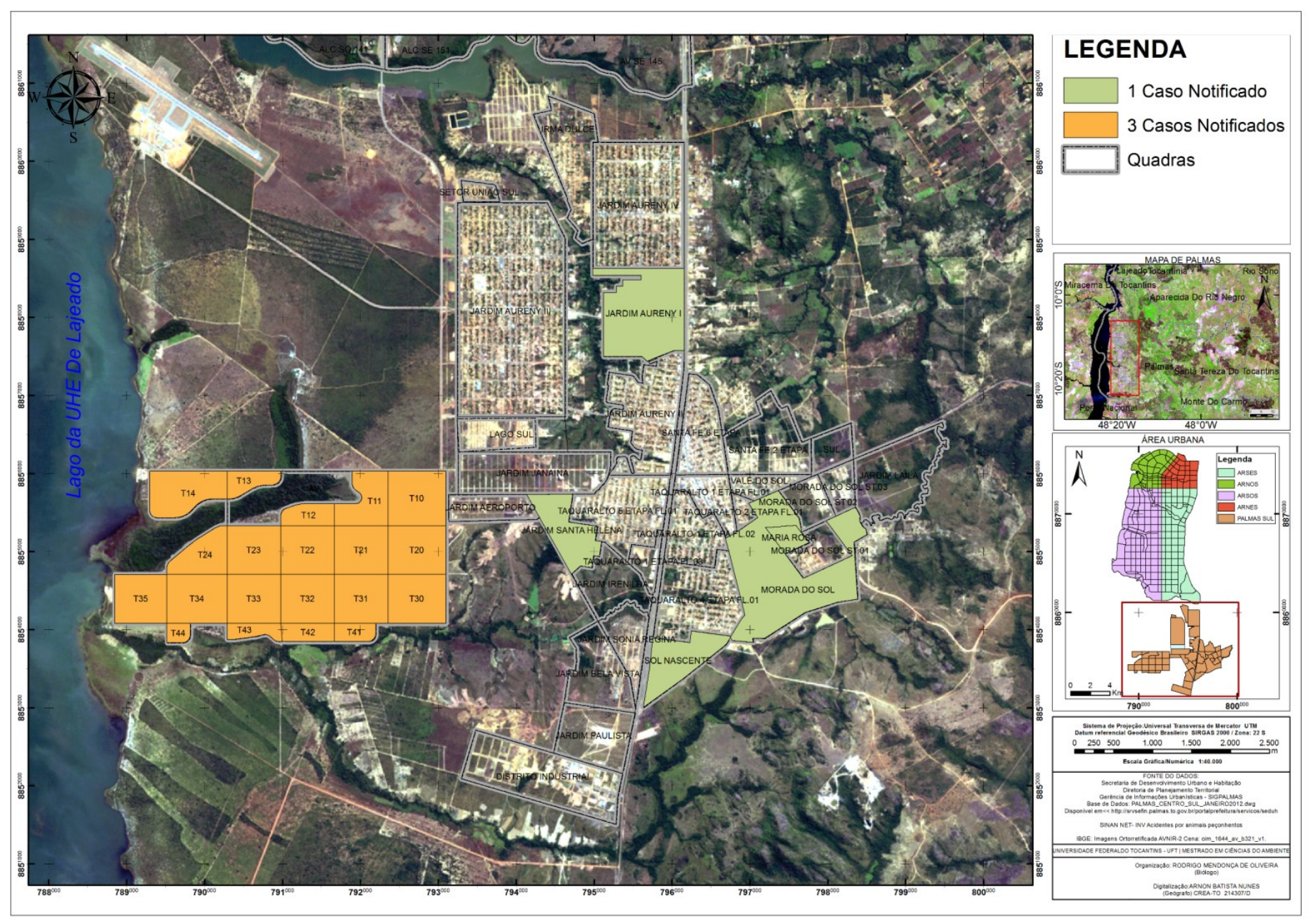


Figura 10 - Mapa de ocorrência dos acidentes por escorpiões nos Bairros da Região Sul do Distrito Sede do município de Palmas-TO, em 2010

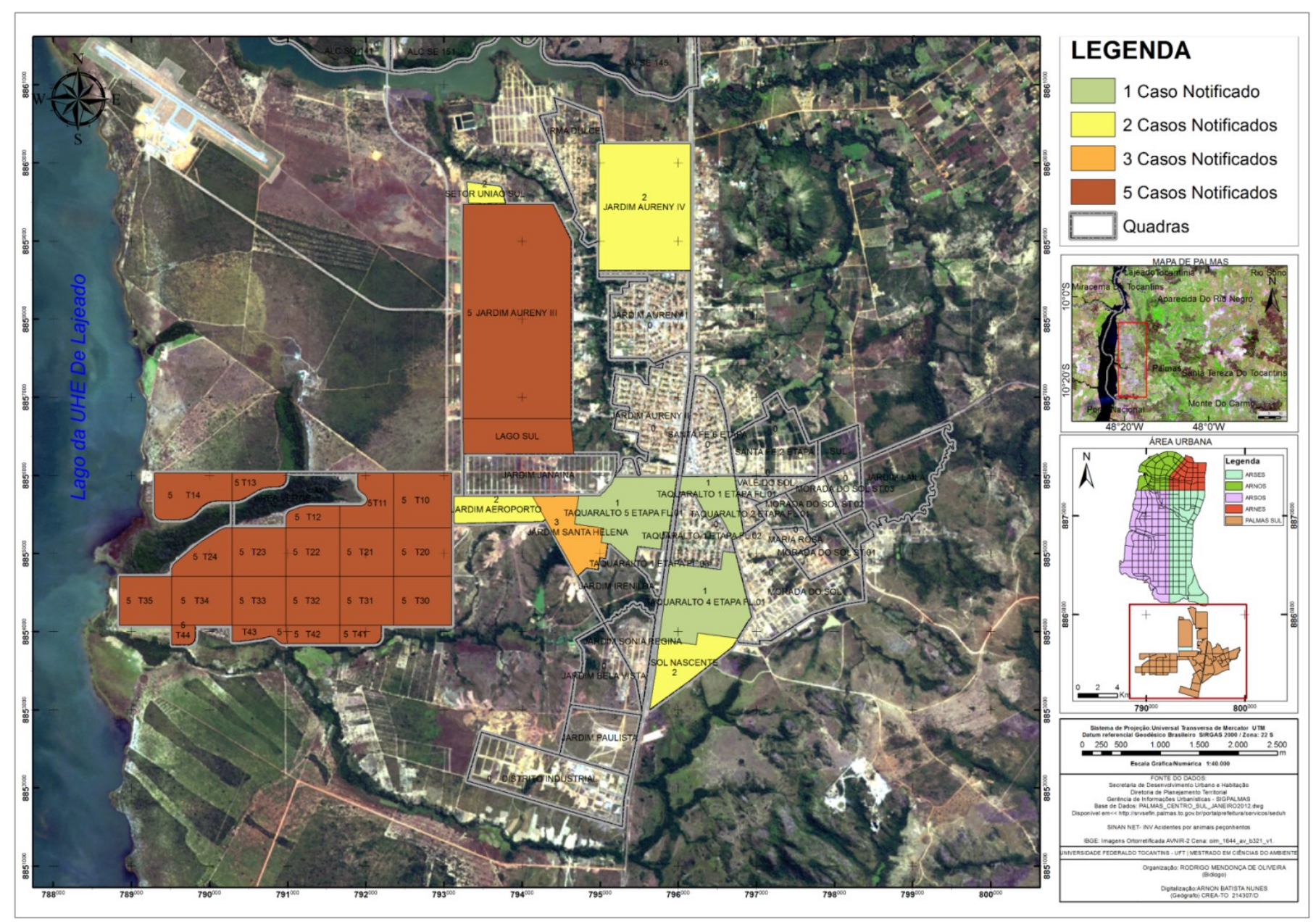


Figura 11 - Mapa de ocorrência dos acidentes por escorpiões nos Bairros da Região Sul do Distrito Sede do município de Palmas-TO, em 2013

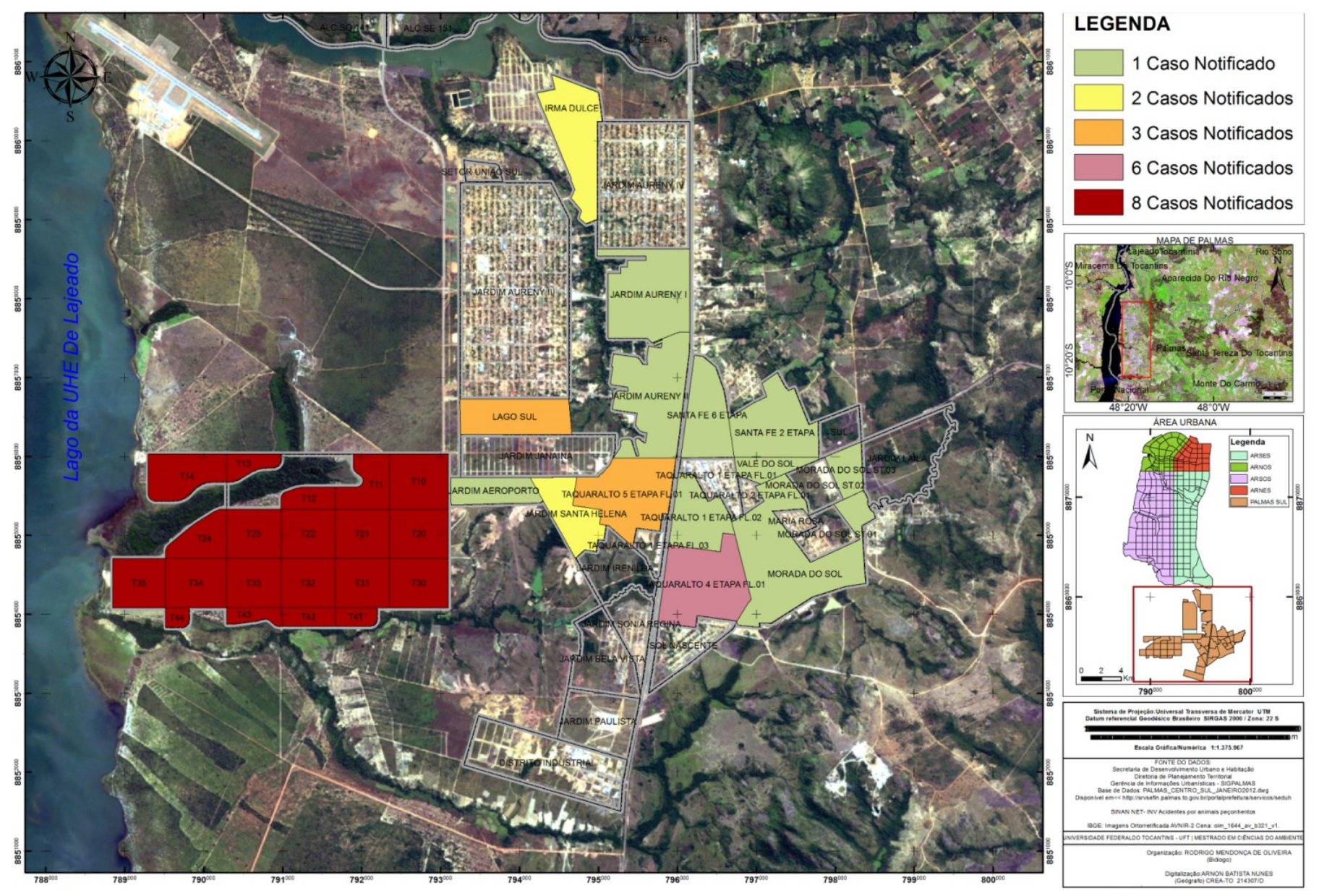


Figura 12 - Uso da terra do Distrito Sede do município de Palmas-TO, para os anos de 2007, 2010 e 2013

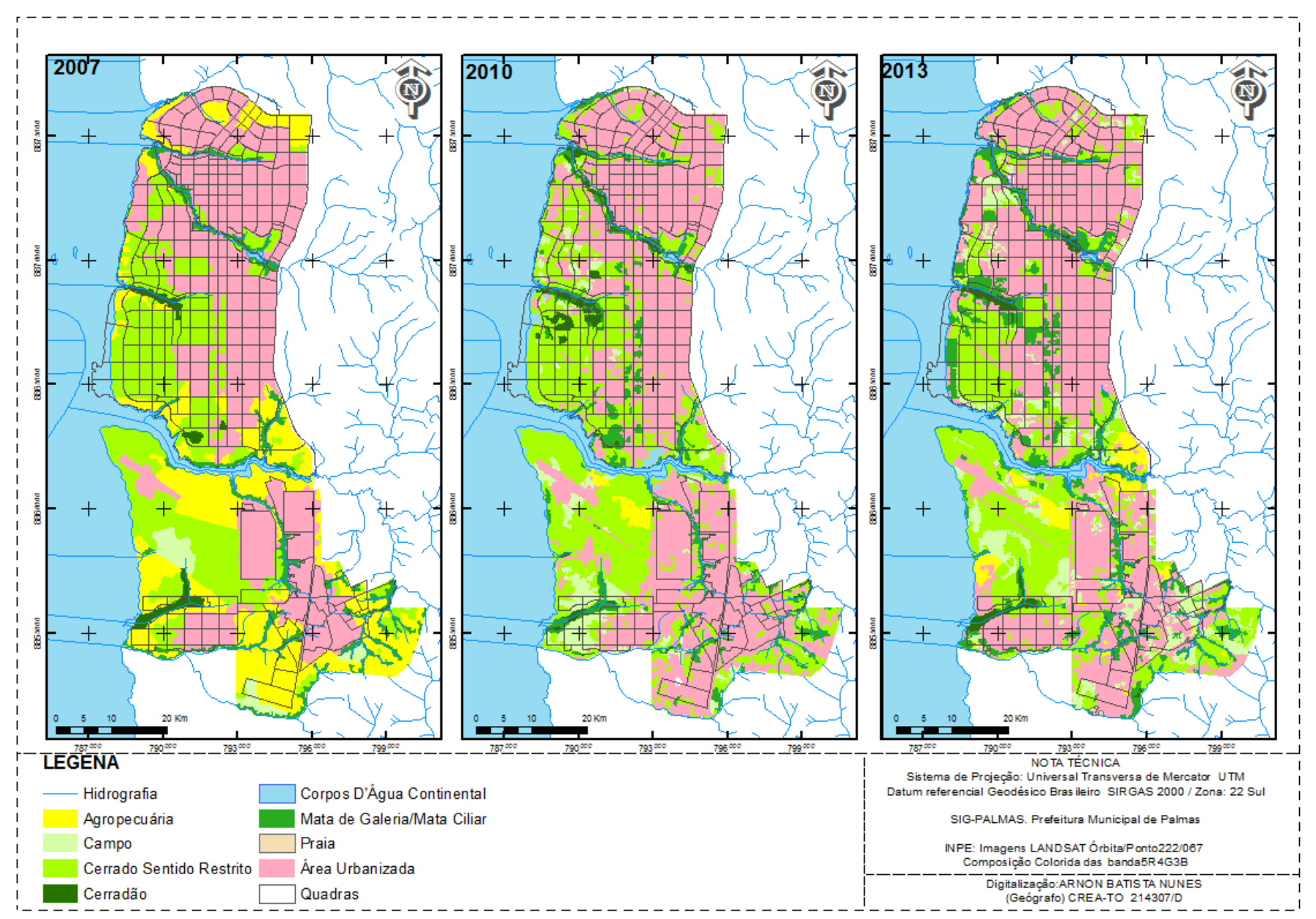

Fonte: Palmas (s/d) 
Rodrigo Mendonça de Oliveira

Sandro Sidnei Vargas de Cristo

O escorpionismo na área urbana de Palmas-Tocantins Heguel Belmiro Souto de Albuquerque

Késia Abreu dos Santos Porto Jorge Luiz de Souza Carla Simone Seibert

Figura 13 - Distribuição das espécies de escorpiões coletados no município de Palmas-TO, entre 2013 e 2014

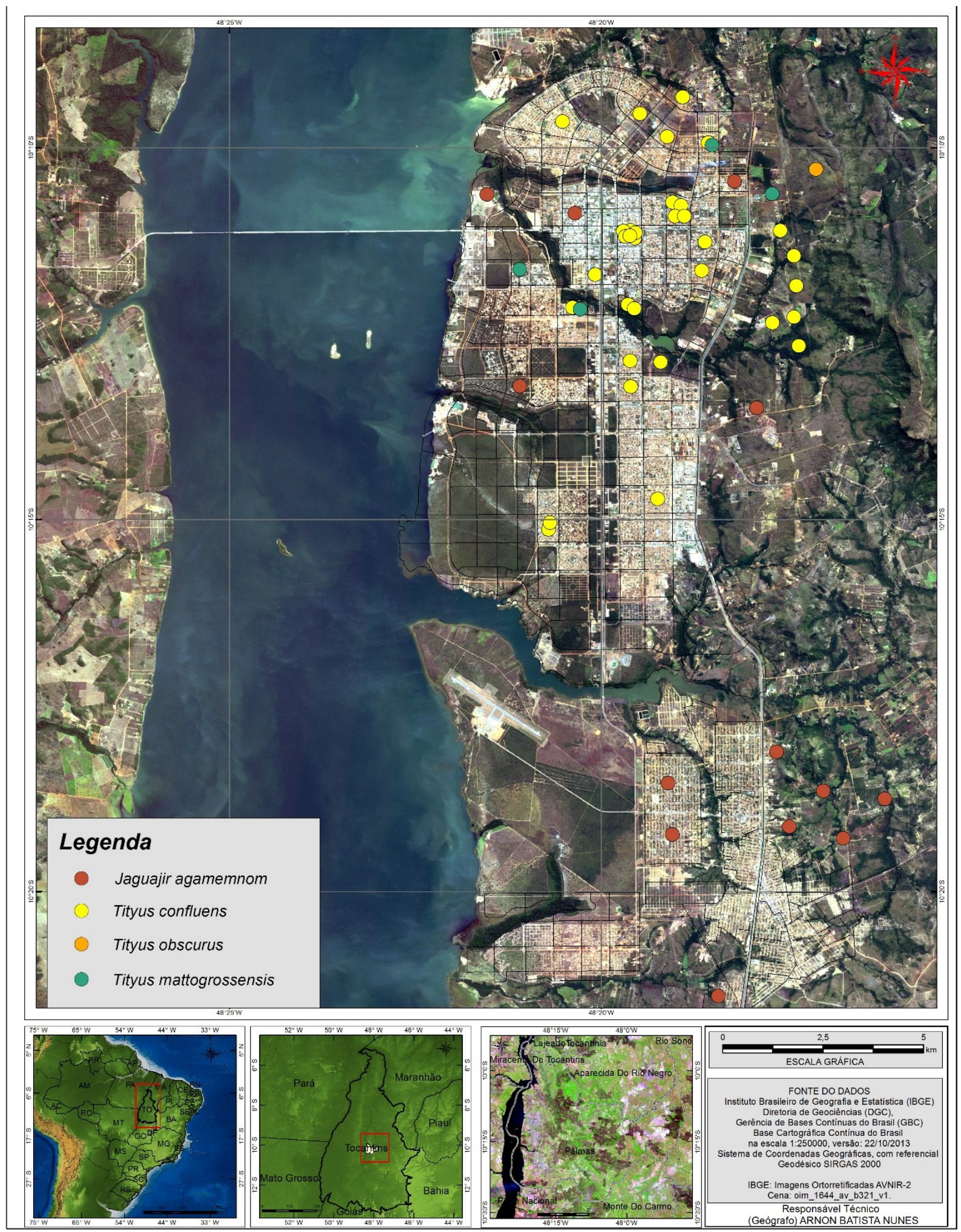

Fonte: Centro de Controle de Zoonoses (CCZ) 


\section{CONSIDERAÇÕES FINAIS}

Os dados epidemiológicos aqui apresentados demonstraram crescente aumento nos registros de acidentes por escorpiões em Palmas. Este fato pode ser influenciado pelo incremento da urbanização, o que envolve alterações do ambiente, as condições socioeconômicas e culturais da população e o planejamento urbano da cidade. A ocupação de novos espaços vem acompanhada do aumento populacional e da maior produção de lixo, que aumenta a fonte alimentar dos escorpiões (baratas e outros insetos) no ambiente urbano, propiciando sua proliferação. É importante também destacar que o aumento das notificações também está atrelado a melhorias na estruturação do serviço de vigilância ambiental, com orientações aos profissionais de saúde para efetivar a notificação dos acidentes.

Portanto, a incidência dos acidentes por escorpiões é crescente e exige ações de combate a proliferação dos mesmos. Os gestores municipais necessitam direcionar esforços para orientar a população no controle da proliferação dos escorpiões, informando da importância dos cuidados com a limpeza do ambiente, o adequado armazenamento do lixo, e ainda, da necessidade de fechar os espaços que possibilitem a entrada do animal nas residências. Desta forma, através de ações básicas, será possível reduzir o número de pessoas acidentadas por escorpiões.

A definição das áreas prioritárias deve embasar uma mobilização dos serviços de saúde, visando criar planos prospectivos para que haja melhoria da eficácia das estratégias de vigilância e controle do agravo no município. Essas ações, por sua vez, devem ser realizadas principalmente pela busca ativa imediata à notificação do acidente e demanda espontânea da população para trabalhos de conscientização eficaz, além de visita às áreas de risco e áreas limítrofes. Para planejamento de tais ações, devem-se considerar também as diferenças internas de cada região, no que diz respeito ao nível de informação e condição socioeconômica dos moradores, condições ambientais e tipo de uso e ocupação do espaço.

\section{REFERÊNCIAS}

BRANDÃO, R. A.; MOTTA, P. C. Acidente por Rhopalurus agamemnon (Koch, 1839) (Scorpiones, Buthidae). Revista da Sociedade Brasileira de Medicina Tropical. v. 43, n. 3, p.342-344, 2010. https://doi.org/10.1590/S0037-86822010000300027

BRASIL. Manual de Diagnóstico e tratamento dos acidentes por Animais Peçonhentos. Brasília: Ministério da Saúde. Fundação Nacional de Saúde, 2001.

BRASIL. Manual de controle do Escorpião.Ministério Da Saúde, Secretaria de Vigilância em Saúde, Departamento de Vigilância Epidemiológica, Brasilia/DF, 2009. (Série B. Textos Básicos de Saúde. Tiragem: $1^{\text {a }}$ edição - 2009).

CARDOSO, J. L. C. José de Anchieta e as Cartas. In: CARDOSO, J. L.; et al. (org). Animais Peçonhentos no Brasil: Biologia, Clínica e Terapêutica dos Acidentes. São Paulo: Sarvier. 2003.

CARVALHÊDO, W. S. Segregação Urbana: uma análise sócio-espacial da capital Palmas/TO. Porto Nacional: Artigo (Graduação de Licenciatura Plena em Geografia) - Universidade Federal do Tocantins, 2007.

CUPO, P.; AZEVEDO-MARQUES, M.M.; HERING, S.E. Acidentes por animais peçonhentos: escorpiões e aranhas. Medicina, v.36, p.490-497, 2003. https://doi.org/10.11606/issn.21767262.v36i2/4p490-497

CUPO, P. Clinical up date on scorpion envenoming. Revista da Sociedade Brasileira de Medicina Tropical. n. 48, v. 6, p. 642-649, 2015. https://doi.org/10.1590/0037-8682-0237-2015

ESPOSITO, L.A., YAMAGUTI, H.Y., SOUZA, C.A., PINTO-DA-ROCHA, R., PRENDINI, L. Systematic revision of the neotropical club-tailedscorpions, Physoctonus, Rhopalurus, and Troglo rhopalurus, revalidation of Heteroctenus, and descriptionsof two new genera and three new species (Buthidae: Rhopalurusinae). BULLETIN OF THE AMERICAN MUSEUM OF NATURAL HISTORY. Number 415, 134 pp. 2017. https://doi.org/10.1206/0003-0090-415.1.1 
GOPALAKRISHNAKONE P., POSSANI, L.D., SCHWARTZ, E.F., DE LAVEGA, R.C.R. Editors. SCORPION VENOMS. Library of Congress Control Number: 2014953827. \# Springer Science+Business Media Dordrecht. 2015. https://doi.org/10.1007/978-94-007-6404-0

KRAN, F.; FERREIRA, F. P. M. Qualidade de vida na cidade de Palmas - TO: uma análise através de indicadores habitacionais e ambientais urbanos. Ambiente \& Sociedade, v. IX, n. 2, 2006. https://doi.org/10.1590/S1414-753X2006000200007

LEOBAS, G. F.; FEITOSA, S. B.; SEIBERT, C. S. Acidentes por animais peçonhentos no estado do Tocantins: aspectos clínico-epidemiológicos. Desafios, v. 2, n. 02. p.269-282. 2016.

LIRA, R.M.S.; JORDÃO, G.M.; SILVA, T.F.; CANDIDO, D.M.; Brazil, T.K. Ocorrência de Rhopalurus debilis (C.L. Koch, 1840) (Scorpiones, Buthidae) no Estado da Bahia, Brasil. Biota Neotropica. v. 05, 2005. https://doi.org/10.20873/uft.2359-3652.2016v2n2p269

LOURENÇO, W. R.Contribution à lacom naissancesystématiquedes Scorpions appartenantau "complexe» Tityus trivittatus Kraepelin, 1898 (Buthidae).Bulletin Du Muséumnational d'Histoirenaturelle, Paris, 4e sér.,v. 2, n.A3,p.793-843, 1980.

LOURENÇO, W. R. Revisão crítica das espécies Tityus do Estado do Pará (Scorpiones, Buthidae). Boletim do Museu Paraense Emilio Goeldi. Serie Zool., v.I, n.I, p.5-18, 1984.

LOURENÇO, W.R. Considérations biogéographiques, écologiques et évolutives surles espèces néotropicales d'Opisthacanthus Peters, 1861 (Scorpiones, Ischnuridae). Studies on Neotropical Fauna and Environment, v. 23, n. 1, p. 21-53, 1988.

LOURENÇO, W.R. 2002.Scorpions of Brazil. Les Editions de I'IF, Paris, 307pp.

LOURENÇO, W. R.; CABRAL, B. C.; RAMOS, E. C. B. Confirmatiom of Tityus confluens BORELLI, 1899 (Scorpiones, Buthidae) in Brasil and description of a new subspecies from the state of Mato Grosso do Sul. Boln. S.E.A., n. 34, p. 27 - 30, 2004. https://doi.org/10.1080/01650528809360742

MAURY, E. A. Escorpiofauna Chaqueña. II. Tityus confluens Borelli 1899 (Buthidae). Physis (C), n. 33, v.86, p. 85-92, 1974.SINAN/SVS/MS. Sistema de Informação de Agravos de Notificação- SINAN, Ministério da Saúde, 2020.

PALMAS. Caderno Revisão do Plano Diretor de Palmas IPUD. Secretaria Municipal de Desenvolvimento Urbano e Habitação SEDUH ,Palmas, 2002.

PARDAL, P. P. O.; CASTRO, L. C.; JENNINGS, E.; PARDAL, J. S. O.Aspectos Epidemiológicos e clínicos do escorpionismo na região de Santarém, Estado do Pará, Brasil/Revista da Sociedade Brasileira de Medicina Tropical., v. 36, n. 3, p.349-353, 2003. https://doi.org/10.1590/S003786822003000300006

POLIS, G. A. The Biology of Scorpions. California: Stanford University Press, p.587, 1990.

PRENDINI, L.; WHEELER, W. C. Scorpion higher phylogeny and classification, taxonomic anarchy, and standards for peer review in online publishing. Cladistics, v. 21, n. 5, p.446-494, 2005. https://doi.org/10.1111/j.1096-0031.2005.00073.x

PARISI, E. V. Vigilância e monitoramento dos acidentes por animais peçonhentos no município de Palmas, Tocantins, Brasil. Revista Brasileira de Geografia Médica e da Saúde. n. 12, v. 22, p. 72 87, 2016.

TORRES, J. B.; MARQUES, M. G. B.; MARTINI, R. K.; BORGES, C. V. A. Acidente por Tityus serrulatus e suas complicações epidemiológicas no Rio Grande do Sul. Revista de Saúde Pública, v.36, n. 5, São Paulo, 2002. https://doi.org/10.1590/S0034-89102002000600014 